\title{
CP110 and its network of partners coordinately regulate cilia assembly
}

William Y Tsang ${ }^{1,2,3^{*}}$ and Brian D Dynlacht ${ }^{4}$

\begin{abstract}
Cilia are hair-like protrusions found at the surface of most eukaryotic cells. They can be divided into two types, motile and non-motile. Motile cilia are found in a restricted number of cell types, are generally present in large numbers, and beat in a coordinated fashion to generate fluid flow or locomotion. Non-motile or primary cilia, on the other hand, are detected in many different cell types, appear once per cell, and primarily function to transmit signals from the extracellular milieu to the cell nucleus. Defects in cilia formation, function, or maintenance are known to cause a bewildering set of human diseases, or ciliopathies, typified by retinal degeneration, renal failure and cystic kidneys, obesity, liver dysfunction, and neurological disorders. A common denominator between motile and primary cilia is their structural similarity, as both types of cilia are composed of an axoneme, the ciliary backbone that is made up of microtubules emanating from a mother centriole/basal body anchored to the cell membrane, surrounded by a ciliary membrane continuous with the plasma membrane. This structural similarity is indicative of a universal mechanism of cilia assembly involving a common set of molecular players and a sophisticated, highly regulated series of molecular events. In this review, we will mainly focus on recent advances in our understanding of the regulatory mechanisms underlying cilia assembly, with special attention paid to the centriolar protein, CP110, its interacting partner Cep290, and the various downstream molecular players and events leading to intraflagellar transport (IFT), a process that mediates the bidirectional movement of protein cargos along the axoneme and that is essential for cilia formation and maintenance.
\end{abstract}

Keywords: Centrosomes, Cilia, Ciliogenesis, CP110, Cep290, BBSome, IFT, Protein network

\section{Review}

Links between cilia, centrosomes, and the cell cycle It is well known that cilia and centrosomes share an intimate relationship during the cell cycle. A centrosome consists of a pair of centrioles, termed the mother and daughter centrioles, embedded in a poorly defined pericentriolar matrix, from which cytoplasmic microtubules emanate and grow [1-4]. The mother centriole can be distinguished from the daughter centriole by the presence of distal and sub-distal appendages. Distal appendages are thought to be important for the docking of a basal body to the cell membrane and the recruitment of IFT proteins prior to cilia assembly, whereas sub-distal appendages anchor microtubules, participate

\footnotetext{
* Correspondence: william.tsang@ircm.qc.ca

'Institut de recherches cliniques de Montréal, 110 avenue des Pins Ouest, Montréal, QC H2W 1R7, Canada

${ }^{2}$ Faculté de Médecine, Université de Montréal, Montréal, QC H3C 3J7, Canada Full list of author information is available at the end of the article
}

in endosome recycling, and form the basal foot, a structure essential for ciliogenesis and ciliary beating in motile cilia [5-9]. In proliferating cells, a single centrosome in the G1 phase undergoes duplication in the $\mathrm{S}$ phase. The two centrosomes then separate, migrating to opposite poles and establishing a bipolar spindle in mitosis. Upon cell cycle exit, a centrosome obtains competence for ciliogenesis, whereby the mother centriole is converted into the basal body. Depending on the cell type and/or cilia type, the basal body can migrate and anchor to the cell surface or dock ciliary vesicles, which elongate and eventually fuse with the plasma membrane. In both scenarios, the basal body serves to nucleate the growth of axonemal microtubules, a process highly dependent on IFT [10-12]. IFT is bidirectional, and this property can be explained by the existence of biochemically and functionally distinct protein complexes, IFT-B and IFT-A. While IFT-B and IFT-A are commonly believed to direct anterograde (cell body to
C Biomed Central

(c) 2013 Tsang and Dynlacht; licensee BioMed Central Ltd. This is an Open Access article distributed under the terms of the Creative Commons Attribution License (http://creativecommons.org/licenses/by/2.0), which permits unrestricted use,

distribution, and reproduction in any medium, provided the original work is properly cited. 
cilia) and retrograde (cilia to cell body) transport of macromolecules, respectively, recent evidence indicates that IFT-A is also involved in anterograde transport [13-16]. IFT is essential for cilium assembly and maintenance, since the organelle lacks protein synthesis machinery [17]. When cells re-enter the cell cycle, cilia are disassembled, and the basal body relocates to the cell interior, assuming a position near the nucleus. It is logical to postulate that controls must exist to suppress the inappropriate assembly of cilia in proliferating cells or the untimely assembly of a bipolar spindle in non-proliferating cells. In addition, vesicular trafficking, mother centriole/basal body migration to the cell surface, basal body anchoring to the cell membrane, and IFT must be tightly regulated in a temporally-, spatially-, and cell-type-specific manner to ensure the fidelity of ciliogenesis. Indeed, a growing number of proteins, including many that were originally identified in a proteomic screen for novel centrosomal and ciliary components [18-20], are known to modulate cilia assembly in a positive or negative manner [21,22], suggesting that cilia assembly involves a complex circuitry controlled by the coordinated inhibition of negative regulators and recruitment and activation of positive regulators.

\section{The CP110-Cep97 pathway}

While there are many important modulators of ciliogenesis, two distal centriolar proteins, CP110 and Cep97, were the first proteins shown to negatively regulate cilia assembly [23]. Loss of either protein elicits premature inappropriate cilium formation in proliferating cells, whereas its over-expression inhibits ciliogenesis in non-proliferating cells. Fittingly, patients with chronic rhinosinusitis, a respiratory disease associated with abnormal or lack of motile cilia, have elevated levels of CP110 [24]. While the precise function of Cep97 awaits further experimentation, this protein might serve as a chaperone to stabilize CP110, allowing the co-recruitment of both proteins to the centrosome. $\mathrm{CP} 110$, on the other hand, is thought to impose a structural role at the centrosome and forms discrete complexes critical for cell cycle regulation and cilia assembly (Figure 1) [23,25-31]. This protein does not have an associated enzymatic activity; rather, it was shown to localize to the distal ends of centrioles, forming a 'cap' above the growing microtubules that could restrain microtubule growth [32]. Indeed, $\mathrm{CP} 110$ has the ability to control centriole length in non-ciliated human [33-35] and insect cells [36] and to block ciliary axoneme formation in ciliated mammalian (RPE-1 and NIH-3T3) cells [23,25]. Paradoxically, CP110 does not modulate cilia length, suggesting that at least in ciliated cells, CP110 could 'switch off' the ciliogenic program. Tellingly, CP110 is completely extinguished from the basal body in ciliated cells (Figure 1 and [23]). The loss of CP110 effectively liberates the mother centriole from its centrosomal role in cell division and 'licenses' the transition from mother centriole to basal body. Thus, it appears that the removal of CP110 from the mother centriole, rather than cell cycle control per se, could play a crucial role in the initiation of ciliogenesis.

CP110 levels and localization to the centrosome are tightly regulated in a cell cycle dependent manner [29]. CP110 protein levels drop significantly in G2/M and G0/G1 phases as a consequence of transcriptional controls, ubiquitin-mediated proteasomal destruction, and microRNA-mediated turnover of CP110 mRNA [37-39]. Furthermore, disappearance of CP110 from the basal body in quiescent cells coincides with an enrichment of a serine/threonine kinase, Ttbk2, at the same location (Figure 2) [40]. Ttbk2, a microtubule plus-end tracking protein, likely promotes the onset of ciliogenesis by cooperating with end binding proteins [40-42]. Depletion of Ttbk2 impairs both the loss of CP110 and the recruitment of IFT complexes, including IFT88, a protein localized to the distal appendages of the emerging basal body and/or the transition zone [40]. Further, the loss of Cep83, a distal appendage protein that functions in a concerted and hierarchical manner to recruit other proteins (including Cep89, SCLT1, FBF1, and Cep164), prevents the recruitment of Ttbk 2 to, and the release of CP110 from, the basal body, thereby blocking basal body anchoring to the cell membrane (Figure 2) [43]. Another study highlighted a role for CCDC41/Cep83 in the recruitment of IFT20 to the basal body and ciliary vesicle docking to the mother centriole as important functions of CCDC41/Cep83 during early ciliogenesis, although Cep164 localization and abundance were not substantially impacted [44]. Since Cep83 and Cep164 can recruit IFT proteins to the basal body and/or the transition zone, these results imply that distal appendage proteins, Ttbk2, CP110, and IFT proteins could functionally interact $[43,45]$. In addition to Ttbk2, the loss of a second serine/threonine kinase, MARK4, causes mis-localization of its interacting partner, Odf2, which is normally found at sub-distal appendages, and likewise, inhibits cilia formation by preventing the removal of CP110/Cep97 from the basal body (Figure 2) [46-48]. In light of recent findings that distal and sub-distal appendages are assembled independently of one another [43], these intriguing observations suggest that Ttbk2 and MARK4 activities might be necessary to modulate the molecular framework of distal and sub-distal appendages, respectively, ultimately leading to the destruction and removal of CP110 from the basal body. Alternatively, the two kinases could function after the assembly of the appendages to remove CP110 [49]. Furthermore, these studies suggest that protein phosphorylation is crucial for the maturation of a mother centriole into a functional basal body, and future phospho-proteomic studies, in combination with 


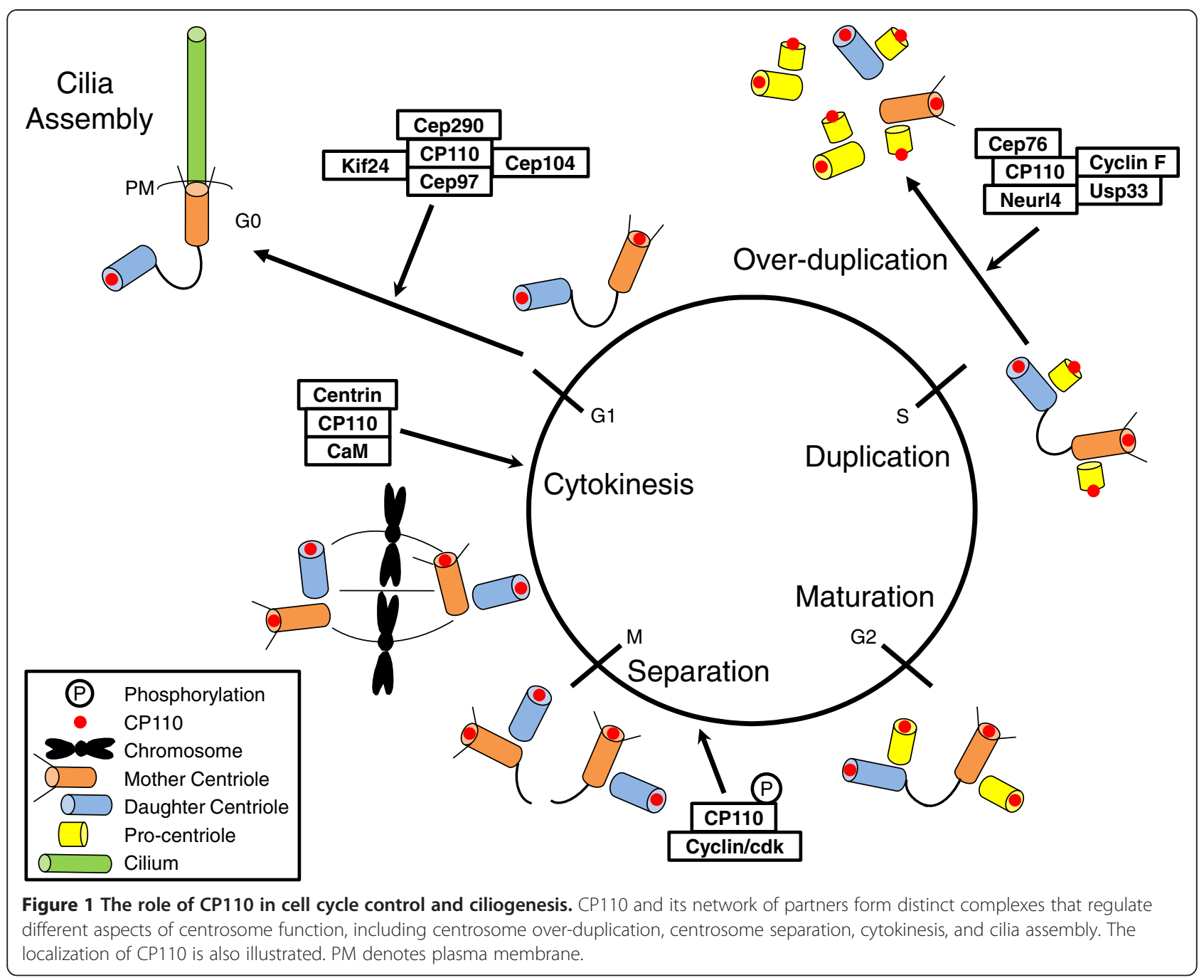

high resolution imaging, will be essential to identify key substrates and to examine these maturation events in greater detail.

\section{CP110-interacting partners and its protein network}

Besides Cep97, CP110 has been shown to associate with a cadre of proteins important for ciliogenesis, suggesting that it could assemble a multi-functional platform to integrate centriolar and basal body functions (Figure 2). Cep104, a microtubule plus-end tracking protein identified by a proteomic screen for novel end bindinginteracting partners, interacts with CP110 and Cep97 [41]. This protein co-localizes with CP110 at the distal ends of centrioles in proliferating cells and is similarly absent from the basal body in quiescent cells. However, unlike CP110 and Cep97, Cep104 is essential for ciliogenesis, suggesting that it may regulate axonemal growth at the onset of cilia assembly by counteracting the activities of CP110 and Cep97. In contrast to Cep104, another protein, Kif24, appears to reinforce the role of CP110 as a suppressor of ciliogenesis [28]. As a member of the microtubule de-polymerizing kinesin family of proteins, Kif24 specifically de-polymerizes and remodels centriolar microtubules at the mother centriole/basal body, and depletion of this protein promotes ciliation, whereas overexpression inhibits cilia growth. Although Kif24 binds CP110 and Cep97, it specifically stabilizes CP110 and recruits it to the centrosome, suggesting that both the de-polymerizing activity of Kif24 and its ability to recruit a distal end capping protein (CP110) to centrioles contribute to cilia suppression. In addition, CP110 has been demonstrated to associate with a human ciliopathy protein, Cep290, (also known as BBS14, NPHP6, JBTS5, SLSN6, MKS4 and LCA10; [25]). Its many names can be attributed to the diverse spectrum of clinical manifestations, including Bardet-Biedl syndrome (BBS), nephronophthisis, Joubert syndrome, Senior-Loken syndrome, Meckel-Gruber syndrome, and Leber congenital amaurosis, associated with mutations in the Cep290 gene [50-52]. Despite the identification of over 


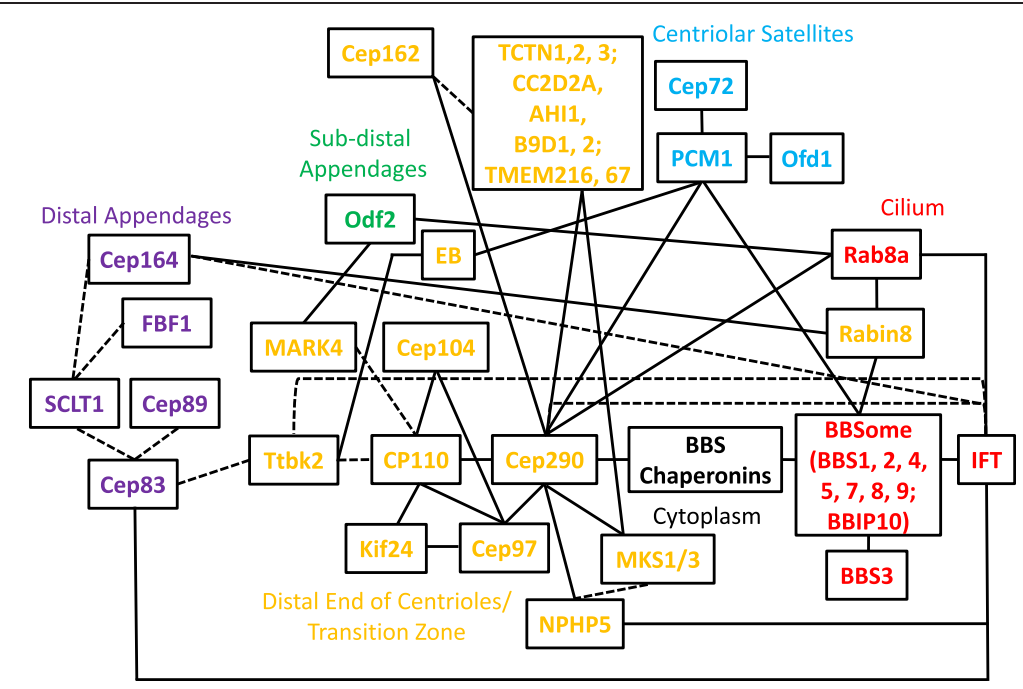

Figure 2 A system-wide schematic of protein interaction networks that modulate cilium assembly. Solid lines indicate known protein-protein interactions, confirmed by immunoprecipitation, yeast two-hybrid, and/or in vitro binding experiments. Not every protein-protein interaction indicated is direct. Dashed lines indicate known functional connections with no evidence of protein-protein interactions to date. EB denotes end binding proteins.

100 unique mutations, there is no clear relationship between genotype and phenotype. The loss of Cep290 abolishes cilia assembly and disrupts the migration/anchoring of centrioles to the cell cortex, suggesting that this protein functions to promote ciliogenesis at an early step of the ciliogenic pathway $[21,25,53]$. This positive function of Cep290 is antagonized by CP110, and overexpression of a CP110 mutant refractory to Cep290 binding is incapable of suppressing ciliation in nonproliferating cells. Because the protein levels of Cep290 remain constant throughout the cell cycle, including G0 [25], it seems plausible that CP110 restrains Cep290 activity in proliferating cells through direct interaction, but once cells exit the cell cycle, the loss of CP110 protein releases Cep290 from inhibition. It is currently not clear how Cep290 might promote centriole migration/anchoring to the cell cortex, although it is known that this protein directly interacts with another ciliopathy protein NPHP5 [54], and depletion of NPHP5 phenocopies the loss of Cep290 [55-57]. Interestingly, analysis of the primary amino acid sequence of Cep290 reveals the presence of multiple $\mathrm{N}$-terminal tropomyosin homology domains and a C-terminal myosin-tail homology domain, suggesting that it might have an actinrelated function, and that centriole migration/anchoring could involve cytoskeletal re-organization and modulation of actin dynamics [51,58]. Indeed, the role of actin cytoskeleton dynamics in cilia assembly has recently been illustrated in a high-throughput RNA interference screen, wherein actin polymerization was shown to have an inhibitory role in cilia assembly [22]. Two proteins belonging to the gelsolin family members, GSN and AVIL, promote ciliation by severing actin filaments. On the other hand, ACTR3, a protein known to mediate the formation of branched actin networks, suppresses cilia formation. Treatment of cells with drugs that inhibit actin filament polymerization and/or affect actin dynamics, such as cytochalasin D or latrunculin B, can facilitate ciliation in addition to causing an increase in cilium length $[22,55]$. Notably, impaired cilia formation associated with the loss of Cep290 or NPHP5 can be restored by the aforementioned drugs, strongly suggesting that proteins involved in the regulation of actin dynamics could influence the ciliogenic pathway and could be exploited as potential therapeutic targets [55]. Besides Cep290 and NPHP5, two other ciliopathy-associated proteins, MKS1 and MKS3, are also required for the translocation of centrioles to the cell surface, whereas IFT88 is not [59]. Thus, it seems likely that a subset of centrosomal proteins is specifically dedicated to basal body migration and anchoring to the cell membrane, and it will be most interesting to identify the complete set of factors that control this important process.

\section{Cep290 function and its protein network}

Beyond its potential contribution in basal body migration and/or anchoring to the cell membrane, Cep290 has additional functions critical to cilia assembly. An elegant ultra-structural study conducted in Chlamydomonas reinhardtii suggests that Cep290 localizes to the transition zone, a small region immediately distal to the basal body characterized by the presence of Y-shaped fibers that connect the axonemal microtubules to the ciliary 
membrane [60]. This region is thought to regulate the entry and exit of protein and lipid cargos into and out of the ciliary compartment. Consistent with this idea, Cep290 is present at the transition zone of rat motile tracheal cilia [61] and associates with CC2D2A and TCTN1, both of which are known to form a large protein complex with several other ciliopathy proteins (AHI1, MKS1, TCTN2, TCTN3, B9D1, B9D2, TMEM216, TMEM67) at the transition zone (Figure 2 and [62-64]). Cep290 also binds to Cep162, an axoneme-recognition protein required for transition zone assembly (Figure 2 and [65]). In addition, Cep290 is required for the targeting of Rab8a, a small GTPase responsible for vesicular trafficking into the cilium in cultured human epithelial cells [25,53], and has a functional connection with the BBSome, a stable multi-subunit complex known to mediate ciliary transport (Figure 2). The BBSome is composed of seven BBS proteins (BBS1, BBS2, BBS4, BBS5, BBS7, BBS8, and BBS9) and $\mathrm{BBIP10}$, a protein required for cytoplasmic microtubule polymerization and acetylation. Assembly of the BBSome follows a hierarchical order that initially involves the stabilization of BBS7 by the chaperonin complex (MKKS/BBS6, BBS10, BBS12 and CCT/TRiC family of chaperonins), followed by the formation of the BBSome core (BBS7, BBS2, BBS9) and the subsequent incorporation of the remaining BBSome subunits through a series of protein-protein interactions [66,67]. Interestingly, two components of the BBSome, BBS4 and BBS8, are not properly recruited to the cilium upon Cep290 loss [68]. The lack of BBSome recruitment to the cilium could be due to an assembly defect, as Cep290 is known to directly interact with MKKS/BBS6, a chaperonin-like molecule required at an early step in BBSome assembly [69]. In addition, a Cep290 mutant in Chlamydomonas reinhardtii possesses malformed flagella with abnormal protein composition, with increased amounts of IFT-B proteins and decreased amounts of IFT-A proteins, suggesting that retrograde and possibly anterograde IFT are impaired [60]. Although neither Cep290 nor CP110 has been demonstrated to directly interact with IFT proteins thus far, a proteomic screen reveals IFT122 as a novel interacting partner of NPHP5 (Figure 2 and [56]), a protein that directly binds to, and shares a number of common features with, Cep290 [55-57]. Further experiments will be necessary to delineate the extent to which the CP110-Cep290 axis overlaps with the BBSome and/or the IFT pathway.

Other than its localization to the transition zone, Cep290 is also targeted to centriolar satellites [53,58]. Centriolar satellites are small, electron-dense proteinaceous granules found in the vicinity of the centrosome and have been implicated in microtubule-dependent protein trafficking towards the centrosome [70-72]. These structures may be closely related to the pericentrosomal pre-ciliary compartment reported at the basal body during the onset of ciliogenesis [22]. Interestingly, several satellite components, including PCM1, BBS4, OFD1, Cep72, and Cep290 are required for cilia assembly, and the integrity of these unique structures is highly dependent on protein-protein interactions between them (Figure 2) $[53,68,73]$. Of note, BBS4 is unique among satellite proteins in that it completely relocalizes from its original satellite position to the cilium during ciliogenesis [74]. Thus, Cep290, together with other satellite proteins, might regulate the trafficking of BBS4 between the two different sub-cellular compartments, and hence play an indirect role in BBSome assembly. Further studies will be needed to decipher the mechanisms through which satellite proteins (and possibly other unidentified associated factors) modulate the number, size, and integrity of satellites in space and time and how such modulation contributes to basal body function, transition zone assembly, and ciliogenesis.

\section{The role of the BBSome and the IFT complex}

BBS is a ciliopathy characterized by renal and retinal failure, obesity, polydactyly, diabetes, hypogenitalism, and hypertension [75]. Seventeen causative genes have been identified so far, and recent studies have begun to unravel the role of BBS proteins in cilia homeostasis. As mentioned earlier, eight different proteins (BBS1, BBS2, BBS4, $\mathrm{BBS5}, \mathrm{BBS7}, \mathrm{BBS} 8, \mathrm{BBS9}$, and $\mathrm{BBIP10)}$ are required to form a functional unit called the BBSome [74,76]. Intriguingly, the BBSome binds Rabin8, a GDP/GTP exchange factor for Rab8a, and directly interacts with phospholipids, suggesting that this complex likely mediates vesicular trafficking during ciliogenesis (Figure 2) [74]. More recently, another BBS subunit, BBS3/Arl6, an Arf-like GTPase, was shown to be a major effector of the BBSome [77]. BBS3/ Arl6 recruits the BBSome to the membrane, where it assembles a 'coat' that sorts proteins to the cilium. This 'coat' recognizes a unique ciliary localization signal found in several ciliary membrane proteins, leading to their efficient trafficking to the cilium [77,78]. Future biochemical and biophysical studies will shed light on the structure of the 'coat' and the precise nature of the ciliary localization signal it recognizes.

Although the BBSome is thought to play an important role in sorting certain membrane proteins to the cilium, neither this complex, nor its assembly factors or BBS3/ Arl6, is generally required for ciliogenesis, as depletion or loss of some of these proteins does not severely impair ciliation but rather leads to defective IFT transport [79-82]. In addition, while BBS knockout mice (BBS1, BBS2, BBS4, BBS6 or BBS7) display subtle phenotypes [81,83-86], a loss of BBS7 in combination with a reduction in IFT function results in a more severe phenotype [85], suggesting that the BBSome and the IFT complex could function in a synergistic manner. These findings have led to the speculation that the BBSome is only 
responsible for transporting a subset of ciliary proteins, whereas the IFT complex is more universally required for all transport processes. Recently, an elegant study which combines a whole-genome mutagenesis screen for mutants with abnormal cilia formation, time-lapse microscopy, and bimolecular fluorescence complementation in Caenorhabditis elegans showed that the BBSome acts on the IFT complex by controlling its assembly and turnaround in cilia [14]. The BBSome first interacts with the IFT complex (Figure 2) and motor proteins to organize them into a functional super-complex. This supercomplex undergoes anterograde transport to the ciliary tip, and once there, the BBSome dissociates from the IFT complex, unloading cargos during the process. The BBSome then re-organizes the IFT complex and reloads new cargos for retrograde transport back to the ciliary base. It remains to be determined if the role of the BBSome in worms is mechanistically conserved in higher eukaryotes, since subtle differences exist in the ciliary structures, and not every BBS subunit is evolutionarily conserved. Nevertheless, elucidating the molecular functions of the individual BBS and IFT components would undoubtedly provide a better understanding of how these two complexes coordinately promote cilia assembly.

\section{Conclusions}

Our knowledge of the architecture of the cilium and the functions of individual ciliary components has expanded considerably in the past 10 to 15 years. The use of forward and reverse genetic screens, animal models, system-wide proteomics, time-lapse microscopy, cryoelectron microscopy, and new innovations in superresolution microscopy have led to rapid and unprecedented breakthroughs in the field, highlighted by many landmark discoveries. Among these, CP110 and Cep290 have emerged as key players in the regulation of the cilia assembly process. Despite our current knowledge of their functions, important questions remain: is CP110 the protein responsible for the conversion of mother centrioles (ciliogenesis incompetent) to basal bodies (ciliogenesis competent), and how are the diverse functions of Cep290 intertwined, if at all, in modulating cilia assembly? We believe that the answers to these questions lie in our ability to decipher and build upon the existing ciliary protein interaction network (Figure 2). These studies should allow us to understand how this network contributes to health and disease and to devise rational therapeutic approaches for treating ciliopathies based on these proteomic and genetic networks.

\section{Abbreviations}

IFT: Intraflagellar transport; BBS: Bardet-Biedl syndrome.

\section{Competing interests}

The authors declare that they have no competing interests.

\section{Authors' contributions}

WYT wrote the manuscript. WYT and BDD revised the manuscript. Both authors read and approved the final manuscript.

\section{Acknowledgements}

We thank Sehyun Kim for critically reading the manuscript, and we apologize to our colleagues whose findings could not be included due to space limitations. WYT was a Canadian Institutes of Health Research New Investigator and a Fonds de Recherché Santé Junior 1 Research Scholar. This work was supported by the Canadian Institutes of Health Research (MOP-115033) to WYT and by an NIH grant (1R01HD069647-01) to BDD.

\section{Author details}

${ }^{1}$ Institut de recherches cliniques de Montréal, 110 avenue des Pins Ouest, Montréal, QC H2W 1R7, Canada. ²Faculté de Médecine, Université de Montréal, Montréal, QC H3C 3J7, Canada. 'Division of Experimental Medicine, McGill University, Montréal, QC H3A 1A3, Canada. ${ }^{4}$ Department of Pathology and Cancer Institute, Smilow Research Center, New York University School of Medicine, New York, NY 10016, USA.

Received: 29 April 2013 Accepted: 3 July 2013

Published: 26 July 2013

\section{References}

1. Brito DA, Gouveia SM, Bettencourt-Dias M (2012) Deconstructing the centriole: structure and number control. Curr Opin Cell Biol 24:4-13

2. Nigg EA, Stearns T (2011) The centrosome cycle: centriole biogenesis, duplication and inherent asymmetries. Nat Cell Biol 13:1154-1160

3. Bettencourt-Dias M, Hildebrandt F, Pellman D, Woods G, Godinho SA (2011) Centrosomes and cilia in human disease. Trends Genet 27:307-315

4. Nigg EA, Raff JW (2009) Centrioles, centrosomes, and cilia in health and disease. Cell 139:663-678

5. Kobayashi T, Dynlacht BD (2011) Regulating the transition from centriole to basal body. J Cell Biol 193:435-444

6. Jana SC, Machado P, Bettencourt-Dias M (2012) A structural road map to unveil basal body composition and assembly. EMBO J 31:519-521

7. Kunimoto K, Yamazaki Y, Nishida T, Shinohara K, Ishikawa H, Hasegawa T, Okanoue T, Hamada H, Noda T, Tamura A, Tsukita S (2012) Coordinated ciliary beating requires Odf2-mediated polarization of basal bodies via basal feet. Cell 148:189-200

8. Kodani A, Salome Sirerol-Piquer M, Seol A, Garcia-Verdugo JM, Reiter JF (2013) Kif3a interacts with dynactin subunit p150 Glued to organize centriole sub-distal appendages. EMBO J 32:597-607

9. Hehnly H, Chen CT, Powers CM, Liu HL, Doxsey S (2012) The centrosome regulates the Rab11-dependent recycling endosome pathway at appendages of the mother centriole. Curr Biol 22:1944-1950

10. Avasthi P, Marshall WF (2012) Stages of ciliogenesis and regulation of ciliary length. Differentiation 83:S30-S42

11. Pedersen LB, Veland IR, Schroder JM, Christensen ST (2008) Assembly of primary cilia. Dev Dyn 237:1993-2006

12. Reiter JF, Blacque OE, Leroux MR (2012) The base of the cilium: roles for transition fibers and the transition zone in ciliary formation, maintenance and compartmentalization. EMBO Rep 13:608-618

13. Mukhopadhyay S, Wen X, Chih B, Nelson CD, Lane WS, Scales SJ, Jackson PK (2010) TULP3 bridges the IFT-A complex and membrane phosphoinositides to promote trafficking of $\mathrm{G}$ protein-coupled receptors into primary cilia. Genes Dev 24:2180-2193

14. Wei Q, Zhang Y, Li Y, Zhang Q, Ling K, Hu J (2012) The BBSome controls IFT assembly and turnaround in cilia. Nat Cell Biol 14:950-957

15. Pedersen LB, Christensen ST (2012) Regulating intraflagellar transport. Nat Cell Biol 14:904-906

16. Liem KF Jr, Ashe A, He M, Satir P, Moran J, Beier D, Wicking C, Anderson KV (2012) The IFT-A complex regulates Shh signaling through cilia structure and membrane protein trafficking. J Cell Biol 197:789-800

17. Ishikawa H, Marshall WF (2011) Ciliogenesis: building the cell's antenna. Nat Rev Mol Cell Biol 12:222-234

18. Andersen JS, Wilkinson CJ, Mayor T, Mortensen P, Nigg EA, Mann M (2003) Proteomic characterization of the human centrosome by protein correlation profiling. Nature 426:570-574 
19. Ostrowski LE, Blackburn K, Radde KM, Moyer MB, Schlatzer DM, Moseley A, Boucher RC (2002) A proteomic analysis of human cilia: identification of novel components. Mol Cell Proteomics 1:451-465

20. Li JB, Gerdes JM, Haycraft CJ, Fan Y, Teslovich TM, May-Simera H, Li H, Blacque OE, Li L, Leitch CC et al (2004) Comparative genomics identifies a flagellar and basal body proteome that includes the BBS5 human disease gene. Cell 117:541-552

21. Graser S, Stierhof YD, Lavoie SB, Gassner OS, Lamla S, Le Clech M, Nigg EA (2007) Cep164, a novel centriole appendage protein required for primary cilium formation. J Cell Biol 179:321-330

22. Kim J, Lee JE, Heynen-Genel S, Suyama E, Ono K, Lee K, Ideker T, Aza-Blanc P, Gleeson JG (2010) Functional genomic screen for modulators of ciliogenesis and cilium length. Nature 464:1048-1051

23. Spektor A, Tsang WY, Khoo D, Dynlacht BD (2007) Cep97 and CP110 suppress a cilia assembly program. Cell 130:678-690

24. Lai Y, Chen B, Shi J, Palmer JN, Kennedy DW, Cohen NA (2011) Inflammationmediated upregulation of centrosomal protein 110, a negative modulator of ciliogenesis, in patients with chronic rhinosinusitis. J Allergy Clin Immunol 128:1207-1215, e1201

25. Tsang WY, Bossard C, Khanna H, Peranen J, Swaroop A, Malhotra V, Dynlacht BD (2008) CP110 suppresses primary cilia formation through its interaction with CEP290, a protein deficient in human ciliary disease. Dev Cell 15:187-197

26. Tsang WY, Spektor A, Luciano DJ, Indjeian VB, Chen Z, Salisbury JL, Sanchez I, Dynlacht BD (2006) CP110 cooperates with two calcium-binding proteins to regulate cytokinesis and genome stability. Mol Biol Cell 17:3423-3434

27. Tsang WY, Spektor A, Vijayakumar S, Bista BR, Li J, Sanchez I, Duensing S, Dynlacht BD (2009) Cep76, a centrosomal protein that specifically restrains centriole reduplication. Dev Cell 16:649-660

28. Kobayashi T, Tsang WY, Li J, Lane W, Dynlacht BD (2011) Centriolar kinesin Kif24 interacts with CP110 to remodel microtubules and regulate ciliogenesis. Cell 145:914-925

29. Chen Z, Indjeian VB, McManus M, Wang L, Dynlacht BD (2002) CP110, a cell cycle-dependent CDK substrate, regulates centrosome duplication in human cells. Dev Cell 3:339-350

30. Li J, Kim S, Kobayashi T, Liang FX, Korzeniewski N, Duensing S, Dynlacht BD (2012) Neurl4, a novel daughter centriole protein, prevents formation of ectopic microtubule organizing centers. EMBO Rep 13:547-553

31. Al-Hakim AK, Bashkurov M, Gingras AC, Durocher D, Pelletier $L$ (2012) Interaction proteomics identify NEURL4 and the HECT E3 ligase HERC2 as novel modulators of centrosome architecture. Mol Cell Proteomics 11:M111 014233

32. Kleylein-Sohn J, Westendorf J, Le Clech M, Habedanck R, Stierhof YD, Nigg EA (2007) Plk4-induced centriole biogenesis in human cells. Dev Cell 13:190-202

33. Schmidt TI, Kleylein-Sohn J, Westendorf J, Le Clech M, Lavoie SB, Stierhof YD, Nigg EA (2009) Control of centriole length by CPAP and CP110. Curr Biol 19:1005-1011

34. Kohlmaier G, Loncarek J, Meng X, McEwen BF, Mogensen MM, Spektor A, Dynlacht BD, Khodjakov A, Gonczy P (2009) Overly long centrioles and defective cell division upon excess of the SAS-4-related protein CPAP. Curr Biol 19:1012-1018

35. Tang CJ, Fu RH, Wu KS, Hsu WB, Tang TK (2009) CPAP is a cell-cycle regulated protein that controls centriole length. Nat Cell Biol 11:825-831

36. Delgehyr N, Rangone H, Fu J, Mao G, Tom B, Riparbelli MG, Callaini G, Glover DM (2012) Klp10A, a microtubule-depolymerizing kinesin-13, cooperates with CP110 to control Drosophila centriole length. Curr Biol 22:502-509

37. Li J, D'Angiolella V, Seeley ES, Kim S, Kobayashi T, Fu W, Campos El, Pagano M, Dynlacht BD (2013) USP33 regulates centrosome biogenesis via deubiquitination of the centriolar protein CP110. Nature 495:255-259

38. D'Angiolella V, Donato V, Vijayakumar S, Saraf A, Florens L, Washburn MP, Dynlacht B, Pagano M (2010) SCF (Cyclin F) controls centrosome homeostasis and mitotic fidelity through CP110 degradation. Nature 466:138-142

39. Cao J, Shen Y, Zhu L, Xu Y, Zhou Y, Wu Z, Li Y, Yan X, Zhu X (2012) miR-129-3p controls cilia assembly by regulating CP110 and actin dynamics. Nat Cell Biol 14:697-706

40. Goetz SC, Liem KF Jr, Anderson KV (2012) The spinocerebellar ataxiaassociated gene Tau tubulin kinase 2 controls the initiation of ciliogenesis. Cell 151:847-858

41. Jiang K, Toedt G, Montenegro Gouveia S, Davey NE, Hua S, van der Vaart B, Grigoriev I, Larsen J, Pedersen LB, Bezstarosti K et al (2012) A Proteome- wide screen for mammalian SxIP motif-containing microtubule plus-end tracking proteins. Curr Biol 22:1800-1807

42. Schroder JM, Larsen J, Komarova Y, Akhmanova A, Thorsteinsson Rl, Grigoriev I, Manguso R, Christensen ST, Pedersen SF, Geimer S, Pedersen LB (2011) EB1 and EB3 promote cilia biogenesis by several centrosome-related mechanisms. J Cell Sci 124:2539-2551

43. Tanos BE, Yang HJ, Soni R, Wang WJ, Macaluso FP, Asara JM, Tsou MF (2013) Centriole distal appendages promote membrane docking, leading to cilia initiation. Genes Dev 27:163-168

44. Joo K, Kim CG, Lee MS, Moon HY, Lee SH, Kim MJ, Kweon HS, Park WY, Kim CH, Gleeson JG, Kim J (2013) CCDC41 is required for ciliary vesicle docking to the mother centriole. Proc Natl Acad Sci U S A 110:5987-5992

45. Schmidt KN, Kuhns S, Neuner A, Hub B, Zentgraf H, Pereira G (2012) Cep164 mediates vesicular docking to the mother centriole during early steps of ciliogenesis. J Cell Biol 199:1083-1101

46. Kuhns S, Schmidt KN, Reymann J, Gilbert DF, Neuner A, Hub B, Carvalho R, Wiedemann P, Zentgraf $\mathrm{H}$, Erfle $\mathrm{H}$ et al (2013) The microtubule affinity regulating kinase MARK4 promotes axoneme extension during early ciliogenesis. J Cell Biol 200:505-522

47. Yoshimura S, Egerer J, Fuchs E, Haas AK, Barr FA (2007) Functional dissection of Rab GTPases involved in primary cilium formation. J Cell Biol 178:363-369

48. Chang J, Seo SG, Lee KH, Nagashima K, Bang JK, Kim BY, Erikson RL, Lee KW, Lee HJ, Park JE, Lee KS (2013) Essential role of Cenexin1, but not Odf2, in ciliogenesis. Cell Cycle 12:655-662

49. Sonnen KF, Schermelleh L, Leonhardt H, Nigg EA (2012) 3D-structured illumination microscopy provides novel insight into architecture of human centrosomes. Biol Open 1:965-976

50. Coppieters F, Lefever S, Leroy BP, De Baere E (2010) CEP290, a gene with many faces: mutation overview and presentation of CEP290base. Hum Mutat 31:1097-1108

51. Sayer JA, Otto EA, OToole JF, Nurnberg G, Kennedy MA, Becker C, Hennies HC, Helou J, Attanasio M, Fausett BV et al (2006) The centrosomal protein nephrocystin-6 is mutated in Joubert syndrome and activates transcription factor ATF4. Nat Genet 38:674-681

52. Valente EM, Silhavy JL, Brancati F, Barrano G, Krishnaswami SR, Castori M, Lancaster MA, Boltshauser E, Boccone L, Al-Gazali L et al (2006) Mutations in CEP290, which encodes a centrosomal protein, cause pleiotropic forms of Joubert syndrome. Nat Genet 38:623-625

53. Kim J, Krishnaswami SR, Gleeson JG (2008) CEP290 interacts with the centriolar satellite component PCM-1 and is required for Rab8 localization to the primary cilium. Hum Mol Genet 17:3796-3805

54. Otto EA, Loeys B, Khanna H, Hellemans J, Sudbrak R, Fan S, Muerb U, OToole JF, Helou J, Attanasio M et al (2005) Nephrocystin-5, a ciliary IQ domain protein, is mutated in Senior-Loken syndrome and interacts with RPGR and calmodulin. Nat Genet 37:282-288

55. Barbelanne M, Song J, Ahmadzai M, Tsang WY (2013) Pathogenic NPHP5 mutations impair protein interaction with Cep290, a prerequisite for ciliogenesis. Hum Mol Genet 22:2482-2494

56. Sang L, Miller JJ, Corbit KC, Giles RH, Brauer MJ, Otto EA, Baye LM, Wen X, Scales SJ, Kwong M et al (2011) Mapping the NPHP-JBTS-MKS protein network reveals ciliopathy disease genes and pathways. Cell 145:513-528

57. Schafer T, Putz M, Lienkamp S, Ganner A, Bergbreiter A, Ramachandran H, Gieloff V, Gerner M, Mattonet C, Czarnecki PG et al (2008) Genetic and physical interaction between the NPHP5 and NPHP6 gene products. Hum Mol Genet 17:3655-3662

58. Chang B, Khanna H, Hawes N, Jimeno D, He S, Lillo C, Parapuram SK, Cheng $\mathrm{H}$, Scott A, Hurd RE et al (2006) In-frame deletion in a novel centrosomal/ciliary protein CEP290/NPHP6 perturbs its interaction with RPGR and results in early-onset retinal degeneration in the rd16 mouse. Hum Mol Genet 15:1847-1857

59. Dawe HR, Smith UM, Cullinane AR, Gerrelli D, Cox P, Badano JL, Blair-Reid S, Sriram N, Katsanis N, Attie-Bitach T et al (2007) The Meckel-Gruber Syndrome proteins MKS1 and meckelin interact and are required for primary cilium formation. Hum Mol Genet 16:173-186

60. Craige B, Tsao CC, Diener DR, Hou Y, Lechtreck KF, Rosenbaum JL, Witman GB (2010) CEP290 tethers flagellar transition zone microtubules to the membrane and regulates flagellar protein content. J Cell Biol 190:927-940

61. Kee HL, Dishinger JF, Blasius TL, Liu CJ, Margolis B, Verhey KJ (2012) A sizeexclusion permeability barrier and nucleoporins characterize a ciliary pore complex that regulates transport into cilia. Nat Cell Biol 14:431-437 
62. Garcia-Gonzalo FR, Corbit KC, Sirerol-Piquer MS, Ramaswami G, Otto EA, Noriega TR, Seol AD, Robinson JF, Bennett CL, Josifova DJ et al (2011) A transition zone complex regulates mammalian ciliogenesis and ciliary membrane composition. Nat Genet 43:776-784

63. Chih B, Liu P, Chinn Y, Chalouni C, Komuves LG, Hass PE, Sandoval W, Peterson AS (2012) A ciliopathy complex at the transition zone protects the cilia as a privileged membrane domain. Nat Cell Biol 14:61-72

64. Gorden NT, Arts HH, Parisi MA, Coene KL, Letteboer SJ, van Beersum SE, Mans DA, Hikida A, Eckert M, Knutzen D et al (2008) CC2D2A is mutated in Joubert syndrome and interacts with the ciliopathy-associated basal body protein CEP290. Am J Hum Genet 83:559-571

65. Wang WJ, Tay HG, Soni R, Perumal GS, Goll MG, Macaluso FP, Asara JM, Amack JD, Bryan Tsou MF (2013) CEP162 is an axoneme-recognition protein promoting ciliary transition zone assembly at the cilia base. Nat Cell Biol 15:591-601

66. Zhang Q, Yu D, Seo S, Stone EM, Sheffield VC (2012) Intrinsic protein-protein interaction-mediated and chaperonin-assisted sequential assembly of stable Bardet-Biedl syndrome protein complex, the BBSome. J Biol Chem 287:20625-20635

67. Seo S, Baye LM, Schulz NP, Beck JS, Zhang Q, Slusarski DC, Sheffield VC (2010) BBS6, BBS10, and BBS12 form a complex with CCT/TRiC family chaperonins and mediate BBSome assembly. Proc Natl Acad Sci U S A 107:1488-1493

68. Stowe TR, Wilkinson CJ, lqbal A, Stearns T (2012) The centriolar satellite proteins Cep72 and Cep290 interact and are required for recruitment of BBS proteins to the cilium. Mol Biol Cell 23:3322-3335

69. Rachel RA, May-Simera HL, Veleri S, Gotoh N, Choi BY, Murga-Zamalloa C, McIntyre JC, Marek J, Lopez I, Hackett AN et al (2012) Combining Cep290 and Mkks ciliopathy alleles in mice rescues sensory defects and restores ciliogenesis. J Clin Invest 122:1233-1245

70. Barenz F, Mayilo D, Gruss OJ (2011) Centriolar satellites: busy orbits around the centrosome. Eur J Cell Biol 90:983-989

71. Kubo A, Sasaki H, Yuba-Kubo A, Tsukita S, Shiina N (1999) Centriolar satellites: molecular characterization, ATP-dependent movement toward centrioles and possible involvement in ciliogenesis. J Cell Biol 147:969-980

72. Dammermann A, Merdes A (2002) Assembly of centrosomal proteins and microtubule organization depends on PCM-1. J Cell Biol 159:255-266

73. Lopes CA, Prosser SL, Romio L, Hirst RA, O'Callaghan C, Woolf AS, Fry AM (2011) Centriolar satellites are assembly points for proteins implicated in human ciliopathies, including oral-facial-digital syndrome 1. J Cell Sci 124:600-612

74. Nachury MV, Loktev AV, Zhang Q, Westlake CJ, Peranen J, Merdes A, Slusarski DC, Scheller RH, Bazan JF, Sheffield VC, Jackson PK (2007) A core complex of BBS proteins cooperates with the GTPase Rab8 to promote ciliary membrane biogenesis. Cell 129:1201-1213

75. Sheffield VC (2010) The blind leading the obese: the molecular pathophysiology of a human obesity syndrome. Trans Am Clin Climatol Assoc 121:172-181, discussion 181-172

76. Loktev AV, Zhang Q, Beck JS, Searby CC, Scheetz TE, Bazan JF, Slusarski DC, Sheffield VC, Jackson PK, Nachury MV (2008) A BBSome subunit links ciliogenesis, microtubule stability, and acetylation. Dev Cell 15:854-865

77. Jin H, White SR, Shida T, Schulz S, Aguiar M, Gygi SP, Bazan JF, Nachury MV (2010) The conserved Bardet-Biedl syndrome proteins assemble a coat that traffics membrane proteins to cilia. Cell 141:1208-1219

78. Berbari NF, Johnson AD, Lewis JS, Askwith CC, Mykytyn K (2008) Identification of ciliary localization sequences within the third intracellular loop of G protein-coupled receptors. Mol Biol Cell 19:1540-1547

79. Lechtreck KF, Johnson EC, Sakai T, Cochran D, Ballif BA, Rush J, Pazour GJ, Ikebe M, Witman GB (2009) The Chlamydomonas reinhardtii BBSome is an IFT cargo required for export of specific signaling proteins from flagella. J Cell Biol 187:1117-1132

80. Yen HJ, Tayeh MK, Mullins RF, Stone EM, Sheffield VC, Slusarski DC (2006) Bardet-Biedl syndrome genes are important in retrograde intracellular trafficking and Kupffer's vesicle cilia function. Hum Mol Genet 15:667-677

81. Mykytyn K, Mullins RF, Andrews M, Chiang AP, Swiderski RE, Yang B, Braun T, Casavant T, Stone EM, Sheffield VC (2004) Bardet-Biedl syndrome type 4 (BBS4)-null mice implicate Bbs4 in flagella formation but not global cilia assembly. Proc Natl Acad Sci U S A 101:8664-8669

82. Shah AS, Farmen SL, Moninger TO, Businga TR, Andrews MP, Bugge $K$, Searby CC, Nishimura D, Brogden KA, Kline JN et al (2008) Loss of Bardet-Biedl syndrome proteins alters the morphology and function of motile cilia in airway epithelia. Proc Natl Acad Sci U S A 105:3380-3385

83. Davis RE, Swiderski RE, Rahmouni K, Nishimura DY, Mullins RF, Agassandian K, Philp AR, Searby CC, Andrews MP, Thompson S et al (2007) A knockin mouse model of the Bardet-Biedl syndrome 1 M390R mutation has cilia defects, ventriculomegaly, retinopathy, and obesity. Proc Natl Acad Sci USA 104:19422-19427

84. Nishimura DY, Fath M, Mullins RF, Searby C, Andrews M, Davis R, Andorf J L, Mykytyn K, Swiderski RE, Yang B et al (2004) Bbs2-null mice have neurosensory deficits, a defect in social dominance, and retinopathy associated with mislocalization of rhodopsin. Proc Natl Acad Sci USA 101:16588-16593

85. Zhang Q, Seo S, Bugge K, Stone EM, Sheffield VC (2012) BBS proteins interact genetically with the IFT pathway to influence SHH-related phenotypes. Hum Mol Genet 21:1945-1953

86. Fath MA, Mullins RF, Searby C, Nishimura DY, Wei J, Rahmouni K, Davis RE, Tayeh MK, Andrews M, Yang B et al (2005) Mkks-null mice have a phenotype resembling Bardet-Biedl syndrome. Hum Mol Genet 14:1109-1118

doi:10.1186/2046-2530-2-9

Cite this article as: Tsang and Dynlacht: CP110 and its network of partners coordinately regulate cilia assembly. Cilia 2013 2:9.

\section{Submit your next manuscript to BioMed Central and take full advantage of:}

- Convenient online submission

- Thorough peer review

- No space constraints or color figure charges

- Immediate publication on acceptance

- Inclusion in PubMed, CAS, Scopus and Google Scholar

- Research which is freely available for redistribution

Submit your manuscript at www.biomedcentral.com/submit 